\title{
Investigation of Most Ideal GNSS Framework (GPS, GLONASS and GALILEO) for Asia Pacific Region (Bangladesh)
}

\author{
Md. Mahmudul Hasan \\ Military Institute Of Science and \\ Technology \\ Mirpur cantt, Dhaka
}

\author{
Redhawan Raziur Rouf \\ Military Institute Of Science and \\ Technology \\ Mirpur cantt, Dhaka
}

\author{
Md. Shajaratul Islam \\ Military Institute Of Science and \\ Technology \\ Mirpur cantt, Dhaka
}

\begin{abstract}
Our paper considers the distinctive route frameworks and tries to recognize the best reasonable route system for Bangladesh. It is required as additional satellites will enhance execution for all applications, and particularly where satellite signs can be clouded, for example, in urban gullies, under tree shelters, or in open-cut mines. The advantages of the normal additional satellites and their signs are expanded accessibility, exactness, congruity, and dependability.
\end{abstract}

\section{General Terms}

Analysis of the DOP Values and Availability of combined GPS/GLONASS/GALILEO Navigation system in Bangladesh and some specific city of the country

\section{Keywords}

GNSS; DOP; Performance analysis

\section{INTRODUCTION}

The necessity of precise GNSS system is undeniable in the present world. The navigation system plays a very vital part in our life and as the world is developing the precision of these GNSS system has very important. ${ }^{[2]}$ Keeping these concept in mind many countries have already developed their own GNSS system. Our aim is to utilize these GNSS system to develop a precise navigation system in the Asia-pacific region where most countries belong to the third world countries.

\section{GLOBAL NAVIGATION SATELLITE SYSTEMS (GNSS)}

\subsection{GPS}

GPS provide the user with a three-dimensional positioning solution (longitude, latitude and altitude) to high precision (within a few meters) using time signal transmitted along a line of sight by radio from satellites. ${ }^{[5]}$ GPS is a one-way ranging (passive) system and it provides continuous positioning and timing information, anywhere in the world. GPS satellites are arranged so that four satellites are placed in each of six orbital planes. With this constellation geometry, four to ten GPS satellites will be visible anywhere in the world, if an elevation angle of $10^{\circ}$ is considered. ${ }^{[9]}$ The orbits are nearly circular and equally spaced around the equator at a $60^{\circ}$ separation with a nominal inclination relative to the equatorial plane of $55^{\circ}$. The nominal orbital period of a GPS satellite is one half of a sidereal day or 11 hours, 58 minutes. In each plane there are four operational satellites. ${ }^{[7]}$ There are 10 different GPS navigation signals, broadcast across three bands, known as link 1 (L1), link 2 (L2) and link 5 (L5). The carrier frequencies are $1575.42 \mathrm{MHz}$ for $\mathrm{L} 1,1227.60 \mathrm{MHz}$ for L2 and 1176.45 MHz for L5, while the declared double-sided signal bandwidth is $30.69 \mathrm{MHz}$ in each band.

\subsection{Galileo}

Galileo system consists of 30 satellites (27 operational +3 active spares), positioned in three circular medium earth orbit (MEO) planes at 23,222 km altitude above the earth and at an inclination of the orbital planed of 56 degrees to the equator. The nominal orbit period is 14 hours, 5 minutes giving 1.7 orbits per sidereal day. ${ }^{[7]}$ Galileo broadcasts 10 different navigation signals across three frequency bands E5, E6 and E1-L1-E2. The E5 band is $92.07 \mathrm{MHz}(90 \times 1.023 \mathrm{MHz})$ wide and centered at $1191.795 \mathrm{MHz}$. It is partitioned into E5a and E5b sub bands, with carrier frequencies of 1176.45 and 1207.14 MHz, respectively. The E6 and E1-L1-E2 bands are both $40.92 \mathrm{MHz}$ wide and centered at 1278.75 and 1575.42 $\mathrm{MHz}$, respectively.

\subsection{GLONASS}

The GLONASS space segment consists of 24 satellites, in three orbital planes, with eight satellites per plane. The GLONASS constellation geometry repeats about once every eight days. The orbit period of each satellite is approximately $8 / 17$ of a sidereall day so that, after eight sidereal days, the GLONASS satellites have completed exactly 17 orbital revolutions. Each orbital plane contains eight equally spaced satellites. ${ }^{[15]}$ One of the satellites will be at the same spot in the sky at the same sidereal time each day. The satellites are placed into nominally circular orbits with target inclinations of 64.8 degrees and an orbital radius of $19,140 \mathrm{~km}$, about $1,060 \mathrm{~km}$ lower than GPS satellites. Each GLONASS satellite transmits on a slightly different L1 and L2 frequency. Frequency band of L1 is $1598.0625-1609.3125 \mathrm{MHz}$ and L2 is $1242.9375-1251.6875 \mathrm{MHz}$

\subsection{DOP}

Dilution of Precision (DOP) is a measure of satellite geometry to indicate the extra multiplicative impact of route satellite geometry on positional estimation precision.[22] The precision of the position assurance are liable to satellites geometric coordination. At least four satellites must be over the spectator's veil plot for the concurrent arrangement of the clock offset and three dimensional receiver's position determination. When the satellite geometry are sufficiently close then the position would probably have an unsatisfactory uncertainty and the DOP, or Dilution of Precision, would be high and when obvious route satellite are far separated and have wide angular separation between the satellites then the 
geometry is said to be strong and DOP value is low. [19] A low DOP represents to a superior GPS positional accuracy because of the more extensive precise partition between the satellites to calculate GPS user position determination.

GPS receivers extracts several parts of DOP, including Horizontal Dilution of Precision (HDOP), which give lateral and longitudinal information while Vertical Dilution of Precision (VDOP) give height information of receiver's position in earth. The mix of these two components provides three-dimensional position data (latitude, longitude and height) is called PDOP - Position Dilution of Precision. A key component of GPS mission arranging is to recognize the season of day when PDOP is limited for a given time and area with known satellite orbit.

\begin{tabular}{|c|c|c|}
\hline $\begin{array}{l}\text { DOP } \\
\text { Value }\end{array}$ & Rating & Description \\
\hline$<1$ & Ideal & $\begin{array}{l}\text { Most astounding conceivable } \\
\text { certainty level to be utilized for } \\
\text { applications requesting the most } \\
\text { astounding conceivable precision } \\
\text { constantly }\end{array}$ \\
\hline $1-2$ & Excellent & $\begin{array}{l}\text { At this certainty level, positional } \\
\text { estimations are viewed as } \\
\text { sufficiently precise to meet } \\
\text { everything except the precise } \\
\text { applications. }\end{array}$ \\
\hline $2-5$ & Good & $\begin{array}{l}\text { Denotes that the base suitable for } \\
\text { settling on business choices. } \\
\text { Positional estimations could be } \\
\text { utilized to make solid in-course } \\
\text { route proposals to the client. }\end{array}$ \\
\hline $5-10$ & Moderate & $\begin{array}{l}\text { Positional estimations could be } \\
\text { utilized for figuring, yet the fix } \\
\text { quality could in any case be made } \\
\text { strides. A more open perspective of } \\
\text { the sky is prescribed. }\end{array}$ \\
\hline $10-20$ & Fair & $\begin{array}{l}\text { Speaks to a low certainty level. } \\
\text { Positional estimations ought to be } \\
\text { disposed of or utilized just to show } \\
\text { a harsh gauge of the present area. }\end{array}$ \\
\hline$>20$ & Poor & $\begin{array}{l}\text { At this level, estimations are off } \\
\text { base by as much as } 300 \text { meters } \\
\text { with a } 6 \text {-meter exact gadget ( } 50 \\
\text { DOP } \times 6 \text { meters) and ought to be } \\
\text { disposed of. }\end{array}$ \\
\hline
\end{tabular}

\subsection{Mathematical equation}

The impact of geometry of the satellites on position error is called Geometric Dilution of Precision and it is generally translated as proportion of position error to the range error. [8] The possibility of Geometric Dilution of Precision (GDOP) is state how error in the estimations will influence the last state estimation.[26] This can be characterized as

GDOP $=(\Delta$ Output area $) /(\Delta$ Measured Data $)$

Error on an estimation bringing about the $\Delta$ Measured Data term evolving. Preferably little changes in the deliberate information won't bring about substantial changes in yield area. All things considered an outcome would show the arrangement is exceptionally sensitive to errors.

The DOP value rely upon covariant framework can be composed as

$$
\operatorname{cov}(\mathrm{dx})=\mathrm{E}\left[\mathrm{HH}^{\mathrm{T}}\right]
$$

Where $\mathrm{dx}$ is the pseudo range error. The matrix $\mathrm{H}$ can be represents as the 'visibility matrix', by and large it can state as $\mathrm{n} \times 4$ matrix. The $\mathrm{H}$ matrix implies Hierarchical matrix. In numerical arithmetic, hierarchical matrix (H-matrix) are utilized as information save estimate of non-save networks. While $\mathrm{H}^{\mathrm{T}}$ is called pseudo inverse.

$$
H=\left[\begin{array}{cccc}
r_{x_{1}} & r_{x_{2}} & r_{x_{3}} & r_{x_{4}} \\
r_{y_{1}} & r_{y_{2}} & r_{y_{3}} & r_{y_{4}} \\
r_{z_{1}} & r_{z_{2}} & r_{z_{3}} & r_{z_{4}} \\
1 & 1 & 1 & 1
\end{array}\right]
$$

Furthermore,

$$
H^{T}=\left[\begin{array}{llll}
r_{x_{1}} & r_{y_{1}} & r_{z_{1}} & 1 \\
r_{x_{2}} & r_{y_{2}} & r_{z_{2}} & 1 \\
r_{x_{3}} & r_{y_{3}} & r_{z_{3}} & 1 \\
r_{x_{4}} & r_{y_{4}} & r_{z_{4}} & 1
\end{array}\right]
$$

Presently to decide the covariance of $\mathrm{dx}$ we duplicate $\mathrm{H}$ matrix and transverse of $\mathrm{H}$ matrix.

$$
\begin{aligned}
H H^{T} & =\left[\begin{array}{cccc}
r_{x_{1}} & r_{x_{2}} & r_{x_{3}} & r_{x_{4}} \\
r_{y_{1}} & r_{y_{2}} & r_{y_{3}} & r_{y_{4}} \\
r_{z_{1}} & r_{z_{2}} & r_{z_{3}} & r_{z_{4}} \\
1 & 1 & 1 & 1
\end{array}\right]\left[\begin{array}{llll}
r_{x_{1}} & r_{y_{1}} & r_{z_{1}} & 1 \\
r_{x_{2}} & r_{y_{2}} & r_{z_{2}} & 1 \\
r_{x_{3}} & r_{y_{3}} & r_{z_{3}} & 1 \\
r_{x_{4}} & r_{y_{4}} & r_{z_{4}} & 1
\end{array}\right] \\
& \left.=\left[\begin{array}{cccc}
\sum r_{X_{i}}^{2} & \cdot & \cdot & \cdot \\
\cdot & \sum r_{y_{i}}^{2} & \cdot & \cdot \\
\cdot & \cdot & \sum r_{z_{i}}^{2} & \cdot \\
\cdot & \cdot & \cdot & 4
\end{array}\right] \text { (where } \mathrm{i}=1,2,3,4\right) \\
& =\left[\begin{array}{cccc}
r_{11} & \cdot & \cdot & \cdot \\
\cdot & r_{22} & \cdot & 1 \\
\cdot & \cdot & r_{33} & 1 \\
\cdot & \cdot & \cdot & r_{44}
\end{array}\right]
\end{aligned}
$$

In this way, in the terms of $\sigma$ the $\operatorname{cov}(\mathrm{dx})$ will be

$$
\operatorname{cov}(d x)=\left[\begin{array}{cccc}
\varphi_{x_{u}}^{2} & \cdot & \cdot & \cdot \\
\cdot & \varphi_{y_{u}}^{2} & \cdot & 1 \\
\cdot & \cdot & \varphi_{z_{u}}^{2} & 1 \\
\cdot & \cdot & \cdot & \varphi_{c t_{b}}^{2}
\end{array}\right]
$$

GDOP is given by the diagonal estimation of the matrix. Which speaks to the enhancement of the standard deviation $\left(\sigma_{\text {ue re }}{ }^{2}\right)$ of the estimation mistakes onto the position arrangement. The GDOP is acquired from the hint of $\left(\mathrm{HH}^{\mathrm{T}}\right)^{-1}$.

$$
\text { Let } \beta=\mathrm{r}^{(-1)}
$$

So, we can write GDOP $=\sqrt{\beta_{11}+\beta_{22}+\beta_{33}+\beta_{44}}$

$$
\begin{aligned}
& \text { GDOP } \geq \sqrt{\frac{1}{r_{11}}+\frac{1}{r_{22}}+\frac{1}{r_{33}}+\frac{1}{r_{44}}} \\
& \text { GDOP }=\sqrt{\frac{\varphi_{x_{u}}^{2}+\varphi_{y_{u}}^{2}+\varphi_{z_{u}}^{2}+\varphi_{c t_{b}}^{2}}{\varphi_{\text {uere }}}}
\end{aligned}
$$




\section{SIMULATION}

We have carried out simulation to obtain the sky plot, no of satellite and DOP. For every GNSS we have kept the latitude and longitude fixed. Other influencing factors such as elevation was also kept constant. Furthermore all the readings were taken at a particular day (25/09/2017) within an hour from the same location. The results are as given bellow.

\subsection{Bangladesh}

.For Bangladesh we have taken lattitude and longitude to be 23.6850 and 90.3563 . The Elevation mask was taken to be $10^{\circ}$. The condition was kept same for all the other GNSS system. As a result we found the following immage.

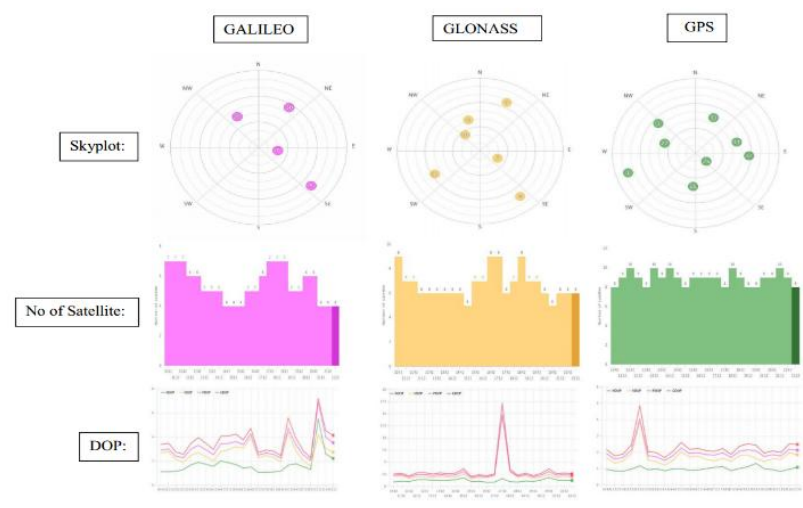

Fig: GNSS radar simulation for Bangladesh

Here we can see for GALILEO we have 4 satellites, for GLONASS we have 6 satellites and for GPS we have 8 satellites. The further comparison of the DOP is done in the next section of this paper.

\subsection{Dhaka}

For Dhaka we have taken lattitude and longitude to be 23.8103 and 90.4125 . The Elevation mask was taken to be $10^{\circ}$. The condition was kept same for all the other GNSS system. As a result we found the following image.

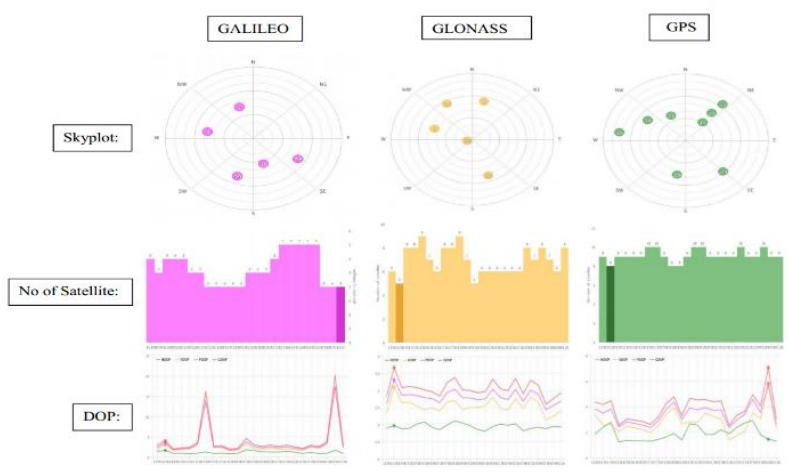

Fig: GNSS radar simulation for Dhaka

Here we can see for GALILEO we have 5 satellites, for GLONASS we have 5 satellites and for GPS we have 8 satellites. The further comparison of the DOP is done in the next section of this paper.

\subsection{Sylhet}

For Sylhet we have taken lat and lon to be 24.9045 and 91.8611. The El mask was taken to be 10 . The condition was kept same for all the other GNSS system. As a result we found the following image.

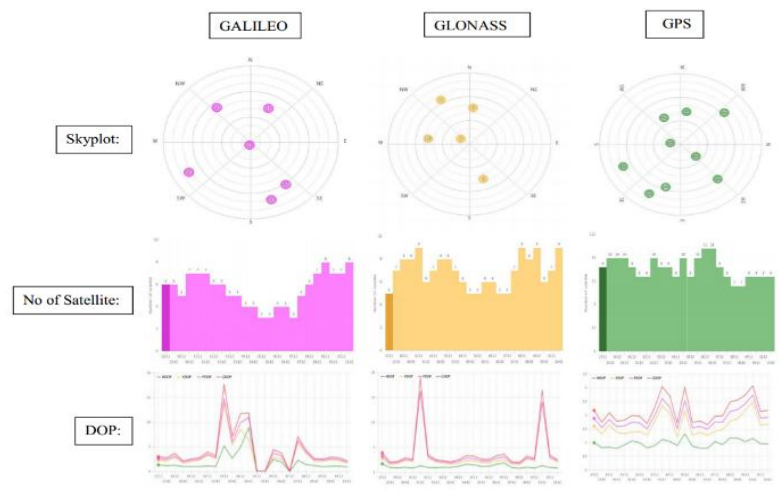

Fig: GNSS radar simulation for Sylhet

Here we can see for GALILEO we have 6 satellites, for GLONASS we have 5 satellites and for GPS we have 9 satellites. The further comparison of the DOP is done in the next section of this paper.

\section{COMPARISON OF GDOP AND PDOP 4.1 Bangladesh}

\begin{tabular}{|l|l|l|l|l|}
\hline GNSS & Location & $\begin{array}{l}\text { Number } \\
\text { of } \\
\text { visible } \\
\text { satellite } \\
\text { at } \\
\text { present } \\
\text { time }\end{array}$ & GDOP & PDOP \\
\hline GPS & Bangladesh & 8 to 10 & 1.8 to & $\begin{array}{l}1.5 \text { to } \\
4.8\end{array}$ \\
\hline Galileo & Bangladesh & 4 to 7 & $\begin{array}{l}2.1 \text { to } \\
7\end{array}$ & $\begin{array}{l}2 \text { to } \\
6.8\end{array}$ \\
\hline GLONASS & Bangladesh & 5 to 9 & $\begin{array}{l}2.4 \text { to } \\
17.5\end{array}$ & $\begin{array}{l}2.4 \text { to } \\
15\end{array}$ \\
\hline
\end{tabular}

GPS is respectively $31.42 \%$ and $72.57 \%$ better than Galileo and GLONASS. And Galileo also $60 \%$ better than GLONASS. In PDOP analysis we also found that GPS is respectively $41.17 \%$ and $73.33 \%$ better than Galileo and GLONASS. And Galileo is $54.66 \%$ better than GLONASS.

\subsection{Dhaka}

\begin{tabular}{|c|c|c|c|c|}
\hline GNSS & location & $\begin{array}{l}\text { Number } \\
\text { of satellite } \\
\text { at a } \\
\text { present } \\
\text { time }\end{array}$ & GDOP & PDOP \\
\hline GPS & Dhaka & 8 to 10 & $\begin{array}{ll}1.6 & \text { to } \\
2.67 & \end{array}$ & $\begin{array}{l}1.48 \\
\text { to } \\
2.38\end{array}$ \\
\hline Galileo & Dhaka & 4 to 7 & $\begin{array}{ll}2.5 & \text { to } \\
7.06 & \end{array}$ & $\begin{array}{l}2.4 \text { to } \\
6\end{array}$ \\
\hline GLONASS & Dhaka & 5 to 9 & $\begin{array}{ll}2 & \text { to } \\
20.15 & \end{array}$ & $\begin{array}{l}2 \text { to } \\
17.5\end{array}$ \\
\hline
\end{tabular}


better than Galileo and GLONASS. And Galileo is 7.8\% better than GLONASS. And for PDOP analysis GPS is respectively $81.73 \%$ and $83.19 \%$ better than Galileo and GLONASS. And Galileo is $7.9 \%$ better than GLONASS.

\subsection{Sylhet}

\begin{tabular}{|c|c|c|c|c|}
\hline GNSS & location & $\begin{array}{c}\text { Number } \\
\text { of visible } \\
\text { satellite at } \\
\text { present } \\
\text { time }\end{array}$ & GDOP & PDOP \\
\hline GPS & Sylhet & 7 to 11 & $\begin{array}{c}1.63 \text { to } \\
3.1\end{array}$ & $\begin{array}{c}1.5 \text { to } \\
2.65\end{array}$ \\
\hline Galileo & Sylhet & 3 to 8 & 0 to & 0 to 15 \\
& & & 17.5 & \\
\hline GLONASS & Sylhet & 5 to 9 & 2 to 19 & 2 to \\
& & & & 16.3 \\
\hline
\end{tabular}

And for Dhaka GPS is respectively $62.18 \%$ and $86.74 \%$ improved than Galileo and GLONASS for GDOP analysis. For PDOP analysis GPS is respectively $60.33 \%$ and $86.4 \%$. And Galileo is $65.71 \%$ better than GLONASS.

\section{OUTCOME}

From the above results we came to know that GPS is better than Galileo and Galileo is better than GLONASS in the context of Asia Pacific region. Hence for better performance we have tried combining GPS and Galileo. And the result was as follows for Bangladesh.

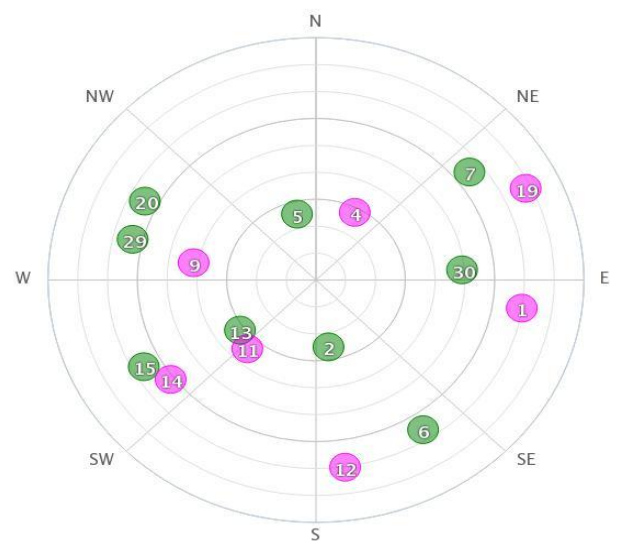

(a)

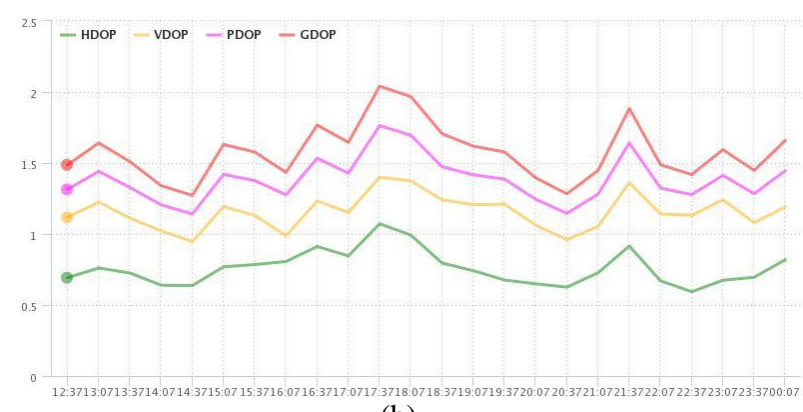

(b)

Fig (a) and (b) Sky plot and DOP graph of GPS and Galileo combined
From the above figures we can conclude that GPS and Galileo combined is $56.25 \%$ in GDOP and $57.5 \%$ in PDOP better than GPS for Bangladesh.

\section{CONCLUSION}

Thus it can be concluded from the above calculations and interpretations that for Asia-Pacific region the combination of GPS and Galileo is the best possible navigation system as per the DOP result analysis. Hence any device with such a combination will be capable of navigating almost precisely in the Asia-pacific region.

\section{REFERENCES}

[1] Principles of GNSS, Inertial and Multisensor Integrated system. Paul D. Groves, Artech House Inc

[2] Understanding GPS, Principles and Applications. Elliott D. Kaplan, Christopher J. Hagerty, Artech House, Inc.

[3] Hawkins D.M. (1980), Identifications of outliers, Chapman \& Hall, London/ New York.

[4] Gao Y. (1993), Reliability assurance for GPS integrity test, ION GPS1992, Salt Lake City, Utah, September 2224, 567-574.

[5] Teunissen, P.J.G. (1998a). Minimal detectable biases of GPS data. Journal of Geodesy, 72, 236-244.

[6] Salgado, G., S. Abbondanza, R Blondel, and S. Lannelongue (2001), Constellation availability concepts for Galileo. Proc. Of ION NTM, Long Beach CA, January 22-24, 778-786.

[7] Verhagen, S.(2002) Performance Analysis of GPS, Galileo and Integrated GPS-Galileo, ION GPS 2002, Portland, Oregon, September 24-27, 2208-2215.

[8] Verhagen, S. (2002) A New Software tool: Studying the Performance of Global Navigation Satellite Systems. GPS World June 2002.

[9] Dinwiddy, S. E., E. Breeuwer, and J. H. Hahn, "The Galileo System,'’Proc. ENC-GNSS 2004, Rotterdum, Netherlands, 2004.

[10] J Ruiz, L., R. Crescinberi, and E. Breeuwer, "Galileo Services Definition and Navigation Performance," Proc. ENC-GNSS 2004, Rotterdam, the Netherlands, 2004.

[11] GPS Satellite Surveying, Alfred Leick, John Wiley \& Sons.

[12] Baarda, W. (1968). A testing procedure for use in geodetic networks. Netherlands Geodetic Commission, Publications on Geodesy, 2(5).

[13] The U.S. Coast Guard Navigation Centre website. Current almanac file is available: http://navcen.uscg.gov/?pageName=gpsAlmanacs

[14] P.Banerjee and Anindya Bose, " Study on the Reliability and Availability of GPS Signal in India

[15] (SRAGI)", March 1997, NPL, New Delhi Abdel-salam, M.A.T., 2005. Precise point positioning using undifferenced code and carrier phase observations, $\mathrm{PhD}$ Thesis, University of Calgary, Canada.

[16] Beutler, G., 2001. Bernese GPS software version 4.2, eds Hugentobler. U., Schaer, S., Fridez, P., Astronomical 
Institute, University of Berne, Switzerland.

[17] Bisnath, S., 2009. Current state of precise point positioning and future prospects and limitations. In Observing our changing earth (615-623). Springer Berlin Heidelberg.

[18] Cai, C. and Gao, Y., 2007. Precise point positioning using combined GPS and GLONASS observations. Journal of Global Positioning Systems, 6(1): 13-22

[19] Cai, C., 2008. Estimation of GPS-GLONASS system time difference with application to PPP. In Proceedings of ION GNSS, 14(9): 16-19.

[20] Cai, C., 2009. Precise point positioning using dualfrequency GPS and GLONASS measurements. In Masters Abstracts International, 48(03): 172 p.

[21] Cai, C. and Gao, Y., 2013. Modeling and assessment of combined GPS/GLONASS precise point positioning.
GPS solutions, 17(2): 223-236.

[22] Estey, L.H. and Meertens, C.M., 1999. TEQC: the multipurpose toolkit for GPS/GLONASS data. GPS solutions, 3(1):42-49.

[23] Gao, Y., 2009. A combined GPS/GLONASS navigation algorithm for use with limited satellite visibility. Journal of Navigation, 62(04): 671-685.

[24] Gioia, C., 2013. Performance assessment of GPS/GLONASS single point positioning in an urban environment. Acta Geodaetica et Geophysica, 48(2):149161 .

[25] Hernandez-Pajares, M., 2010. The ESA/UPC GNSS-Lab Tool (gLAB). In Proc. of the 5th ESA Workshop on Satellite

[26] wikipedia.org/wiki/Dilution_of_precision_(navigation). 